\title{
O aprendizado da língua portuguesa em tempos de modernidade líquida: algumas considerações sobre a aprendizagem da leitura e da escrita de pessoas idosas no Brasil e em Moçambique
}

\author{
The learning of Portuguese Language in times of \\ Liquid Modernity: some considerations about the \\ learning of reading and writing by \\ aged people in Brazil and Mozambique
}

\author{
Nilce da SILVA \\ Patrícia Claudia da COSTA
}

\section{RESUMO}

Este artigo pretende cotejar, ainda que de maneira inicial, o aprendizado de mulheres idosas, de acordo com as realidades brasileira e moçambicana. O conceito de "escrita terceirizada", construído pelas autoras, e de "modernidade líquida" (Z. Bauman) são de fundamental importância para a análise da aprendizagem da Língua Portuguesa por pessoas idosas na cidade de Guarulhos e Maputo. Finalmente, faremos considerações acerca da exigência da rapidez imposta pelos dias atuais em grandes centros, mesmo que, muitas vezes, o tempo necessário para que a aprendizagem da leitura e da escrita ocorra seja contrariamente mais lento.

Palavras-chave: alfabetização, escrita terceirizada, Guarulhos, Maputo, modernidade líquida, pessoas idosas.

\begin{abstract}
This article aspires to compare, even in an initial manner, the learning constructed by aged women, according to Brazilian and Mozambiquean realities. The concept of "outsourced writing", created by the authors, and of "liquid modernity" (Z. Bauman) are extremely important to analyze the learning of Portuguese Language by aged people in the cities of Guarulhos and Maputo. Finally, the authors make some considerations about the exigency of quickness established nowadays in big cities, although many times
\end{abstract}


this necessity of speed is contrary to the necessary time for learning, in this case, to read and to write.

Index Terms: aged people, alphabetization, Guarulhos, Maputo, liquid modernity, outsourced writing.

\title{
RÉSUMÉ
}

Cet article sert à pouvoir examiner, l'apprentissage des femmes âgées, d'après les réalités brésilienne et mozambicaine. Le concept "écriture par un tiers", élaboré par les auteurs, et de la « modernité fluide » (Z. Bauman) ont une importance capitale concernant l'analyse de l'apprentissage de la Langue Portugaise par des personnes âgées dans la ville de Guarulhos et de Maputo. Finalement, nous ferons des considérations concernant l'exigence de la rapidité imposée par les jours actuels dans les grands centres, même si quelques fois, le temps nécessaire à l'apprentissage n'est pas toujours celui qui est attendu, en ce qui concerne la lecture et l'écriture.

Mots clés: apprentissage, écriture par un tiers, Guarulhos, Maputo, modernité fluide, personnes âgées.

\section{Introdução}

Minha mãe até hoje na cidade dela faz as coisas dela, vai ao banco,

tudo dependendo dos outros. Ela paga para as pessoas fazer. Tem uma senhora lá que faz tudo a papelada dela que precisa do sítio. Ela vai lá sozinha e faz. Mas, ela não sabe nada, nada, nada. Se perguntar que letra é essa, ela não sabe se é um $O$ ou se é um $A$. E já viveu quase 80 anos.

(Almeida)

\begin{abstract}
Ao receber o seu [diploma], Alima sente o seu coração bater de tal modo que se surpreende por ainda o conservar no peito. Para ela, não é apenas um modesto certificado de quarta classe que segura com ambas as mãos, mas o testemunho do seu grande esforço para levantar o véu que encerra um mundo de infinitos horizontes, com o qual sempre sonhou desde criança.
\end{abstract}

(Lília Momplé, O sonho de Alima, p. 45)

Este artigo pretende cotejar, ainda que de maneira inicial, o aprendizado de mulheres idosas, de acordo com as realidades brasileira e moçambicana. Dentre outros, o conceito de "escrita terceirizada" se constitui como 
um dos elementos que compõe os processos de ensino e aprendizado da língua escrita junto às educandas, sujeitos desta pesquisa.

Representando a realidade brasileira, apresentamos dados de uma pesquisa qualitativa realizada com um grupo de educandas idosas do Movimento de Alfabetização de Jovens e Adultos de Guarulhos (MovaGuarulhos) e que, guardadas as devidas proporções, pode ser de utilidade para a análise e compreensão de outros contextos educacionais. O grupo constituiu-se por sete mulheres com idades entre 60 e 73 anos, todas integrantes de um mesmo núcleo de alfabetização por, no mínimo, um ano. Algumas delas já haviam passado por outras experiências educativas em diferentes etapas de suas vidas e tinham em comum o fato de, em níveis distintos, fazerem uso da escrita terceirizada em seu cotidiano.

O outro grupo de sujeitos sobre o qual trataremos neste artigo é constituído por um grupo de 45 pessoas, moradoras de Maputo, com idade entre 16 e 50 anos ${ }^{1}$ É importante ressaltar que nenhuma destas pessoas teve a Língua Portuguesa como materna e que a aprenderam, na modalidade escrita, majoritariamente, na instituição escolar. Tais sujeitos, durante nossa missão de trabalho em Maputo no mês de março deste ano, falaram-nos, dentre outros assuntos, sobre suas mães, tias, pessoas conhecidas que, por diferentes motivos, até os dias de hoje, falam poucas palavras em Língua Portuguesa, não dominam a escrita da mesma e, quando sentem necessidade deste instrumento na vida social, costumam pedir para seus filhos e netos que realizem determinadas tarefas para elas.

Neste contex to bilateral, Brasil-Moçambique, apresentaremos as definições de escrita terceirizada e de modernidade líquida para que, em se-

1 Dados coletados durante o mês de março de 2008, como parte da missão de trabalho desenvolvida no âmbito do Edital 06/2007 - PROÁFRICA - Chamada 2, Projeto "Resgate da memória social e o papel da Revista Acolhendo a Alfabetização nos Países de Língua Portuguesa como suporte prático-teórico em favor da Lei 11.645/08 que tem como parceiros: Universidade de São Paulo, Universidade Eduardo Mondlane (UEM) e Faculdades Integradas de Bebedouro (FAFIBE). Para conhecer um pouco mais sobre esses sujeitos recomendamos a leitura do artigo "FRAGMENTOS DA MEMÓRIA: cultura e língua portuguesa em Maputo- Homenagem aos irmãos moçambicanos", de Nilce da Silva e Aparecida do Carmo Frigeri Berchior, integrante deste volume da Revista Acolhendo. 
guida, possamos relacioná-las e apontar um dos principais elementos sociais que "facilitam" a possibilidade de delegar a outros a função de escriba no século XXI, a saber: a configuração de um tipo de sociedade — que vem se instalando principalmente nos grandes centros urbanos - que exige a rapidez. Dito de outro modo, a sociedade do fast: fast food e, no caso deste artigo, a fast literacy.

Finalmente, consideraremos que a terceirização da escrita é semelhante a outras formas de "delegar tarefas" cujo objetivo principal é "atingir a rapidez". Assim, o aprender a ler e a escrever pode ser comparado com outras atividades próprias da modernidade líquida, tais como: pedir para o contador fazer o imposto de renda, pedir para o revisor verificar a ortografia dos nossos textos, pedir para o motoboy levar este documento, pedir lanches pelo telefone na hora do jantar, pedir para o despachante ir a determinado órgão, dentre outras atividades consideradas eficazes nos dias de hoje. A terceirização da escrita configura-se, então, como mais um dos fenômenos típicos da era atual. Ou seja, até no momento da aprendizagem da leitura e da escrita, espera-se e exige-se dos educandos a rapidez de todos os fenômenos da modernidade líquida, típicos do século XXI. Os educandos, impelidos por tal exigência, findam por terceirizar a escrita e, para isso, se aliam a um "escriba".

\section{$1 O$ conceito de escrita terceirizada}

A idéia de que o domínio da língua escrita é uma habilidade essencial para a sobrevivência na sociedade atual é tão comum como o preconceito lingüístico sofrido pelos sujeitos que não possuem esse tipo de domínio. No entanto, o que significa de fato "dominar a língua escrita"? Levando em conta que sua produção não prescinde de um sujeito que a determine e a concretize, o que podemos dizer das produções que têm, de fato, dois sujeitos: alguém que determina a escrita e outra pessoa que a concretiza? 
A esse fenômeno damos o nome de "escrita terceirizada" por compreendermos que o ato de delegar a outra pessoa o papel de produtor da escrita, que deveria ou poderia ser um ato do próprio sujeito que a solicita, urge ser compreendido como uma tentativa de não ser completamente excluído da cultura letrada.

Sabemos que a idéia de "terceirização" tem sua origem no campo da Economia, que a define como: "Terceirizar uma atividade nada mais é que repassar a terceiros a sua realização. Em termos empresariais, podemos dizer que é o repasse de uma atividade-MEIO a terceiros. ${ }^{2,}$ No campo do Direito Laboral, a terceirização tem sido compreendida como uma das mudanças provenientes da organização toyotista do trabalho e da reestruturação produtiva. Ela se fundamenta em argumentos de ordem técnica que sustentam uma maior e melhor produtividade, atrelados à diminuição dos custos de produção e, em decorrência, diminuição dos preços, favorecendo o consumo (OLIVEIRA, 2008). O que mais nos importa na transposição do conceito, do campo dos estudos sobre as relações de trabalho para as relações entre sujeito-mundo da escrita, é o fato de que a terceirização caracteriza-se pela presença de um intermediário entre o trabalhador e a empresa que usufrui dos serviços deste, configurando-se como uma estratégia externalizante.

Em termos educacionais, o sentido permanece o mesmo, ao passo que o ato de servir-se da leitura e da escrita de uma terceira pessoa em atividades corriqueiras também se constitui como uma forma de efetivação de uma atividade-meio em diversas dimensões do ser social.

Tal prática nos faz lembrar a figura do "escriba", profissão de grande destaque na Antiguidade e que, de certa forma, tem algumas de suas funções perduradas até os dias atuais. De acordo com Manacorda (2004), o acesso à profissão de escriba se apresentava perante os jovens, em seus primórdios, como uma perspectiva de ascensão social. Suas funções eram as mais diver-

\footnotetext{
2 Disponível em: <http://www.sebraesp.com.br/principal/abrindo\%20seu\%20neg\%C3\%B3cio/produtos\% 20sebrae/artigos/listadeartigos/terceirizacao.aspx>. Acesso em 1 maio 2008.
} 
sas, de acordo com o universo cultural de cada época: escrever os rolos de papiro na casa do rei; instruir seus colegas, ser o mestre das crianças nobres e guiar seus superiores, tudo conforme os ensinamentos de seu rei; conhecer o cerimonial do palácio; especializar-se em seu ofício; ensinar para perpetuar seu conhecimento e o uso que dele se deve fazer, neste caso, a própria função de ensinar se torna o seu ofício, passando a ser denominado mestre. O seu ofício consistia essencialmente em:

[...] dar ordens e também ser enviado como mensageiro, o que em geral significa transmitir ordens: função de evidente prestígio e autoridade, o que pressupõe a aquisição de habilidades pela frequiência a uma verdadeira escola, o que não existe, [na Antiguidade], para os demais ofícios (MANACORDA, 2004, p. 24).

Vemos, então, que a figura do escriba ocupa um lugar de origem bastante privilegiado. À medida que algumas mudanças culturais — tais como a ampliação do número de pessoas alfabetizadas e o desenvolvimento da imprensa - provocaram a diminuição do papel social desses sujeitos, podemos dizer que hoje a função ainda sobrevive, resguardadas as devidas transformações históricas, ou seja, com um caráter distinto e com outras atribuições. No caso aqui estudado, reconhecemos no papel ocupado pelo produtor de escrita terceirizada algumas características similares aos escribas da Antiguidade, principalmente, no que diz respeito ao ato de escrever, em si, e o fato de mostrar-se como alguém que domina o que deve ser instruído. Para compreender a atuação desse sujeito nos dias atuais, por via das experiências do agente terceirizador, observemos algumas características do mundo urbano em que ambos vivem. 


\section{A sociedade liquefeita ${ }^{3}$}

O conceito de "terceirização da escrita" exige uma reflexão sobre a cultura letrada como um palco de encontros ou desencontros de sujeitos e saberes conforme os indivíduos que dela participam tenham construído (ou não) sentidos para a língua escrita, ou seja, tenham aceitado a funcionalidade da letra em sua economia psíquica.

Entendemos por funcionalidade da língua escrita a qualidade estabelecida pelo sujeito para sua relação com o universo letrado, que pode se manifestar em diferentes níveis e, assim, determinar o aprendizado dos mecanismos de codificação e decodificação da língua. De acordo com Silva (2001, 2003), os termos "analfabeto" e "iletrado" devem ser substituídos pela expressão "sujeito em situação de letramento a-funcional", uma vez que a questão da incapacidade de ler e escrever está relacionada a uma situação na qual o sujeito não conseguiu estabelecer um padrão de funcionalidade da escrita em sua economia psíquica, ao invés de traduzir um estado de falta ou ausência de algum atributo - no caso, a capacidade de ler e escrever — tornando-se, desta forma, uma fonte de estigmatização.

Tendo em mente que, em termos sociológicos, o mundo no qual todos nós vivemos possui características que condicionam e aprisionam os indivíduos, no que diz respeito à relação com a língua escrita, pontuaremos algumas observações que nos parecem pertinentes para compreender a relação que alguns sujeitos estabelecem com a escrita. Tomaremos como base de análise os modos de interação com a cultura letrada empreendidos por mulheres idosas em processo de alfabetização e perceberemos como a necessidade de ampliação de seus modos de inserção na cultura letrada, na

\footnotetext{
${ }^{3}$ Esta denominação dada por Bauman $(1999,2000,2001,2003)$ aos tempos atuais deve-se ao fato de que as relações de diferentes tipos estabelecidas em sociedade são como os fluidos: movem-se facilmente. Eles "fluem", "escorrem", “esvaem-se", "respingam", "transbordam", "vazam", "inundam", "borrifam", "pingam", são "filtrados", "destilados"; diferentemente dos sólidos, não são facilmente contidos — contornam certos obstáculos, dissolvem outros e invadem ou inundam seu caminho... Associamos "leveza" ou "ausência de peso" à mobilidade e à inconstância: sabemos pela prática que quanto mais leves viajamos, com maior facilidade e rapidez nos movemos.
} 
perspectiva de ampliação do uso da língua escrita como ferramenta de relação interpessoal e meio de comunicação, sustentam a rotineira terceirização do uso da língua escrita.

Vale lembrar que referimo-nos a indivíduos que nasceram nas décadas de 1930 e 1940; portanto, tiveram uma educação familiar pautada em valores que não coincidem com as características da sociedade atual. Nas palavras de Bauman: “a sociedade que entra no século XXI não é menos 'moderna' que a que entrou no século XX; o máximo que se pode dizer é que ela é moderna de um jeito diferente" (BAUMAN, 2001, p. 36).

Essa sociedade, "moderna de um jeito diferente”, faz com que os moradores de grandes cidades tenham a sensação de impotência sem precedentes, já que, no anseio por esta liberdade, os mesmos encontram-se por sua própria conta e risco em meio ao concreto. A responsabilidade é deixada às energias individuais, favorecendo a solução biográfica das contradições sistêmicas.

No reino do consumo, apesar da riqueza que flui, muitos são os miseráveis, aqueles que vivem do lixo. Além disto, o trabalho não é mais um porto seguro, nem fundamento da vida em sociedade, sobretudo o trabalho da imensa massa dos menos favorecidos economicamente.

Como conseqüência da liquidez desmedida, o tempo nas cidades é do fim da era do engajamento mútuo: todos estão ocupados o tempo todo. A agenda está cheia especialmente para aqueles que, no momento, não podem oferecer alguma espécie de vantagem. Para os "indesejados", oferece-se toda espécie de resposta vinda de um aparelho eletrônico. Estas máquinas, portanto, colaboram para que o descompromisso entre as pessoas seja uma norma: assim, a secretária eletrônica ligada, o correio eletrônico "que não funciona bem", o "computador que pegou vírus", a caixa postal do celular são barreiras colocadas entre nós e aqueles que não queremos atender. E no que diz respeito ao cotidiano dos sujeitos estudados: 
Tem coisa de antigamente que é bem melhor: tinha mais tempo. Aqui em São Paulo tem muita correria. Mesmo que as pessoas querem dar atenção, conversar, dar carinho, a pessoa já não pode. Está correndo para ir para escola, emprego, faculdade. Então, já não tem mais aquele tempo de ter atenção e de ter carinho. Por isso, eu acho que antigamente era bem melhor, sabe... Hoje em dia, as coisas são diferentes, não é todo mundo que tem carinho e atenção. Eu vejo muito desamor... é diferente de antigamente... (Informação verbal).

Todos participam de muitos projetos ao mesmo tempo e não observamos, salvo cada vez menos raríssimas exceções, o nascimento e muito menos o crescimento de fortes vínculos entre as pessoas que se acotovelam na megalópole. Do ponto de vista aqui adotado, as relações humanas na "Selva de Pedra" têm os seguintes aspectos: a fuga, a astúcia, o desvio e a evitação, a efetiva rejeição de qualquer confinamento territorial, com os complicados corolários de construção e manutenção da ordem, e com a responsabilidade pelas conseqüências de tudo, bem como com a necessidade de arcar com os custos (BAUMAN, 2001, p. 18).

Deste modo, a procrastinação - considerada há pouco tempo como demonstração de displicência, indolência ou lassidão - torna-se posição ativa e, portanto, proposital. A identidade de palimpsesto encontra terreno fértil para sua constituição:

Essa é a identidade que se ajusta ao mundo em que a arte de esquecer é um bem não menos, se não mais, importante do que a arte de memorizar, em que esquecer, mais do que aprender, é a condição de contínua adaptação, em que sempre novas coisas e pessoas entram e saem sem muita ou qualquer finalidade do campo de visão da inalterada câmara da atenção, e em que a própria memória é como uma fita de vídeo, sempre pronta a ser apagada a fim de receber novas imagens, e alardeando uma garantia para toda a vida exclusivamente graças a essa admirável perícia de uma incessante auto-obliteração (BAUMAN, 1999, p. 36-37).

\section{Mulheres idosas em Guarulhos}

Guarulhos está localizada a nordeste da Região Metropolitana de São Paulo, sendo um dos 39 municípios que a integram. A cidade é estrategicamente posicionada no planalto paulista, na região brasileira conhecida como 
principal eixo de desenvolvimento, São Paulo—Rio de Janeiro, fica apenas a $17 \mathrm{~km}$ da capital. Sua extensão total é de $341 \mathrm{~km}^{2}$ e, de acordo com dados do Instituto Brasileiro de Geografia e Estatística (IBGE) do ano de 2007, em número de habitantes Guarulhos é a segunda maior cidade do Estado de São Paulo, com mais de um milhão de habitantes, sendo também a segunda maior economia entre os municípios e a sétima colocada no ranking do Produto Interno Bruto (PIB) nacional de cidades.

O crescimento econômico da cidade foi impulsionado por diferentes atividades no decorrer dos séculos: mineração, agricultura, olaria, indústria e, após a inauguração do Aeroporto Internacional de Cumbica em 1985, a prestação de serviços tem-se mostrado como uma das mais importantes atividades econômicas do município. Vale destacar que o Aeroporto Internacional de Cumbica ${ }^{4}$ é o maior aeroporto da América do Sul, com movimento médio superior a 34 mil passageiros/dia, somando uma movimentação anual de 12,6 milhões de passageiros (praticamente 12 vezes o número de habitantes da cidade). $\mathrm{O}$ aeroporto oferece vôos diretos para 80 destinos nacionais e para 75 cidades de 63 países. Disso podemos inferir que Guarulhos é uma cidade "portal" do mundo para o Brasil e vice-versa, na qual a fluidez é metaforizada, nesta megalópole, também pelo fluxo intenso das pessoas que fazem uso do transporte aéreo. No entanto, há de se considerar que os milhares de (i)migrantes que hoje compõem a população da cidade não fizeram uso desta "porta de acesso", inclusive os sujeitos que desta pesquisa participaram. Todas as colaboradoras fizeram uso do transporte terrestre para emigrar de diferentes cidades do Nordeste, de Minas Gerais e do interior de São Paulo. Trata-se de um simples detalhe que faz toda a diferença na caracterização da população estudada, por revelar a precariedade das condições sócio-econômicas nas quais as mulheres sobre quem falamos vivem.

\footnotetext{
${ }^{4}$ Informações da Infraero. Disponível em: <www.infraero.gov.br〉. Acesso em: 24 jan. 2007.
} 
Os números apontados por diferentes censos demonstram um crescimento populacional acelerado do município, a partir dos anos de 1950. Observa-se também que a distribuição etária da população guarulhense declina conforme o avanço dos anos de vida. Considerando as faixas etárias que compõem o foco desta pesquisa, no início deste século, havia na cidade apenas 60.959 pessoas com idade igual ou superior a 60 anos, o que equivale a menos de $1 \%$ do total de habitantes. Tal contingente era composto por 26.539 homens e 34.420 mulheres, acompanhando a tendência do predomínio do gênero feminino nas demais faixas a partir de 15 anos.

Tabela 1 - Distribuição demográfica dos habitantes do município de Guarulhos de acordo com idade e sexo - ano 2000

\begin{tabular}{|c|c|c|}
\hline Faixa etária & Homens & Mulheres \\
\hline 0 a 4 & 55.574 & 53.848 \\
\hline 5 a 9 & 51.328 & 50.137 \\
\hline 10 a 14 & 51.671 & 51.323 \\
\hline 15 a 19 & 52.851 & 54.843 \\
\hline 20 a 24 & 52.314 & 54.412 \\
\hline 25 a 29 & 50.558 & 51.602 \\
\hline 30 a 34 & 47.417 & 48.266 \\
\hline 35 a 39 & 41.278 & 43.300 \\
\hline 40 a 44 & 34.917 & 36.876 \\
\hline 45 a 49 & 27.979 & 29.036 \\
\hline 50 a 54 & 20.947 & 22.050 \\
\hline 55 a 59 & 14.063 & 15.172 \\
\hline 60 a 64 & 10.466 & 11.820 \\
\hline 65 a 69 & 6.789 & 8.693 \\
\hline 70 a 74 & 4.648 & 6.497 \\
\hline 75 a 79 & 2.606 & 3.852 \\
\hline 80 ou mais & 2.030 & 3.558 \\
\hline
\end{tabular}

Fonte: Censo IBGE 2000 , PMG/SDU - Sist. de Inf. Georreferenciadas - SIGeo.

Ainda de acordo com o censo do ano 2000, Guarulhos apresentava um quadro com $39 \%$ de seus habitantes em situação de analfabetismo ${ }^{5}$. Os dados referentes à população de todo o país mostram que os índices aumentam para $48,78 \%{ }^{6}$. Os dados baseiam-se na constatação de que quase $48 \%$

\footnotetext{
${ }^{5} \mathrm{O}$ índice sofre o seguinte desdobramento: $12 \%$ "analfabetos absolutos" e $27 \%$, "analfabetos funcionais". Conforme vimos anteriormente, temos restrições quanto à utilização desses termos. Somos reticentes quanto ao uso do termo "analfabeto" para designar sujeitos que vivem em sociedades de cultura letrada e que ainda não perceberam uma relação de funcionalidade da letra em sua economia psíquica, preferimos a não distinção dos "tipos de analfabetos". Designaríamos o índice total como "sujeitos em situação de letrismo afuncional".

${ }^{6}$ Sendo $13,04 \%$ absolutos e $35,74 \%$, funcionais. Vale comentário da nota anterior.
} 
da população brasileira, com idade igual ou superior a 15 anos, têm no máximo quatro anos de estudo e que, dessas pessoas, 13,04\% nunca chegaram a freqüentar uma escola. Em Guarulhos, estimava-se a existência de 300.000 cidadãos com baixa escolaridade, dos quais 105.000 seriam analfabetos.

Nesse contexto, em 2002, surgiu na cidade o Mova-Guarulhos. De acordo com Costa (2008), a primeira pesquisa de perfil dos educandos do Mova-Guarulhos, realizada em 2004, constituiu-se enquanto primeiro apontamento oficial do significativo número de educandos acima de 60 anos no universo tomado como campo desta pesquisa: cerca de 6,5\%. Também comprovou a existência de uma maioria feminina no quadro de educandos: $62,50 \%$ do total de alunos eram do sexo feminino, enquanto $37,50 \%$ eram do sexo masculino, com distribuição uniforme em praticamente todas as faixas etárias. Em 2006, um novo levantamento apontou aumento do número total de educandos e do crescimento percentual do número de educandos idosos. Além disso, a proporção de mulheres aumentou para $65 \%$, enquanto a parcela masculina caiu para $35 \%$.

É importante notar que - mesmo havendo aumento do número de pessoas em todas as faixas etárias, decorrente da expansão do Movimento na cidade - em termos percentuais, houve diminuição nas faixas com menos de 50 anos e aumento em todas as faixas acima de 50 anos. Tal alteração de composição etária demonstra o inegável crescimento da inserção de sujeitos idosos numa ação alfabetizadora.

Vejamos os dados que confirmam o aumento da procura por alfabetização no segmento etário do qual estamos tratando.

Tabela 2 - Distribuição etária dos educandos do Mova-Guarulhos nos anos de 2004 e 2006

\begin{tabular}{|c|c|c|c|c|}
\hline \multirow{2}{*}{ FAIXA ETÁRIA } & \multicolumn{2}{|c|}{2004} & \multicolumn{2}{c|}{2006} \\
\cline { 2 - 5 } & Números absolutos & Percentual & Números absolutos & Percentual \\
\hline 16 a 20 & 189 & $5 \%$ & 156 & $3,8 \%$ \\
\hline 21 a 30 & 588 & $17 \%$ & 639 & $15,56 \%$ \\
\hline 31 a 40 & 1056 & $30 \%$ & 1142 & $27,81 \%$ \\
\hline 41 a 50 & 960 & $27,5 \%$ & 1013 & $24,67 \%$ \\
\hline
\end{tabular}




\begin{tabular}{|c|c|c|c|c|}
\hline 51 a 60 & 488 & $14 \%$ & 679 & $16,54 \%$ \\
\hline 61 a 70 & 209 & $6 \%$ & 344 & $8,38 \%$ \\
\hline 70 ou mais & 18 & $0,5 \%$ & & \\
\hline 71 a 80 anos & & & 96 & $2,33 \%$ \\
\hline Acima de 80 anos & & & 12 & $0,29 \%$ \\
\hline
\end{tabular}

Fonte: Dados coletados pelos educadores populares e sistematizados pela Equipe de Coordenação Pedagógica do Mova-Guarulhos.

As situações que embasam nossa reflexão sobre a terceirização da escrita, na realidade da maior cidade da Região Metropolitana de São Paulo, fazem parte de uma ampla base de dados coletados, durante o ano de 2006 e 2007, por meio da metodologia de pesquisa-formação autobiografia educativa. Tratou-se de um trabalho de campo preocupado em compreender a motivação dos sujeitos para freqüentar um núcleo de alfabetização no âmbito de um movimento de educação popular. As narrativas autobiográficas compartilhadas no grupo de sete mulheres idosas participantes da pesquisa revelaram que, entre tantas questões, a terceirização da escrita tem sido uma estratégia de tentativa de inserção no mundo letrado, largamente utilizada durante grande parte da vida e inclusive na fase atual (COSTA, 2008).

Por terem nascido e crescido em ambientes rurais, nos quais a cultura letrada não se impunha como um imperativo de integração social, os sujeitos em questão somente tomaram consciência de sua situação de exclusão desta cultura - decorrente da impossibilidade de codificar e decodificar informações em registro escrito — quando começaram a sofrer na pele as dificuldades oriundas de algumas situações sociais típicas de ambientes urbanos. Isso aconteceu a partir da adolescência e em contextos tão distintos que uma análise mais apurada desse "descobrimento" extrapola os limites do presente texto.

$\mathrm{O}$ que pretendemos tratar, por ora, diz respeito às maneiras pelas quais essas mulheres têm enfrentado a premência, cada vez maior, de fazer uso do código escrito numa sociedade na qual a incapacidade de lidar com a escrita em geral - tanto como codificador, quanto como decodificador - 
determina diferentes níveis de exclusão social, inclusive impedindo o acesso a algo que lhe é de direito, tal como a marcação de consultas num hospital público. Para desvencilhar-se da exclusão imposta pelo universo letrado há, no mínimo, duas opções: aprender a ler e a escrever ou delegar a uma terceira pessoa a leitura e a escrita.

Como já mencionado, o que pudemos observar é que a delegação tem sido uma estratégia amplamente utilizada. Passemos a ver alguns exemplos que ilustram nossa reflexão.

\section{Situações reais de escrita terceirizada}

Uma situação bastante comum é aquela na qual o sujeito em situação de letramento a-funcional depende de outrem para preencher algum tipo de formulário. Uma de nossas colaboradoras declarou:

Se eu tiver que preencher alguma coisa em algum lugar, eu peço para alguém fazer por mim. Eu falo mesmo: eu não sei ler e não sei escrever! Por exemplo, no hospital, se der para a funcionária preencher para mim, tudo bem. Se não der, eu levo para casa e minha família preenche. Já aconteceu isso comigo. É uma perda de tempo... Perda de tempo e humilhação. Porque fala com um filho e ele diz: "ah! Eu não gosto de escrever!" Fala com outro: "eu não sei preencher isso!" Poucos ajudam. (Informação pessoal)

Tal situação nos mostra como a terceirização da escrita tem sido experimentada como uma necessidade desconfortável e humilhante. Além de ferir a autonomia do sujeito, colocando-o à mercê da boa vontade alheia, ela dificulta a resolução de problemas cotidianos, tais como preencher uma ficha solicitada num hospital. Imaginemos o tempo e a energia consumidos por um sujeito que precisa levar um formulário para ser preenchido em casa e devolvido posteriormente, ao invés de efetivar sua entrega no ato de recebimento do mesmo. Afirmamos tratar de um tipo de ação que consome não apenas tempo e energia, mas também considerável dose de auto-estima da pessoa que se vê dificultada em uma tarefa que aos outros parece banal. 
Na mesma medida em que o preenchimento de formulários tem se mostrado como uma situação de dilapidação da auto-estima dos sujeitos que dependem da terceirização da escrita para darem conta de situações cotidianas, a necessidade de assinar lista de presença em determinados eventos também tem se mostrado como um detonador da terceirização da escrita.

Um dos sujeitos de nossa pesquisa declarou ter como hábito, nas reuniões que participava em sua paróquia: “disfarçava com a folha na mão até pedir para algum conhecido marcar a presença por mim. Agora, sou eu quem já faz para as minhas amigas que não quiseram vir estudar." Outra senhora informou que a reunião de pais na escola dos filhos é uma das tantas outras situações na qual a terceirização da assinatura também se faz necessária.

Dificuldades na organização dos próprios negócios também foram apontadas como desencadeadoras do processo de terceirização da escrita. $\mathrm{O}$ exemplo mais contundente foi dado por uma das senhoras desta pesquisa que descreveu e analisou o modo como sua mãe tem lidado, durante toda a vida, com a necessidade de resolver tarefas cotidianas relacionadas à manutenção do sítio onde vive. Um excerto de sua análise foi utilizada como epígrafe deste artigo. Vale destacar que a dependência, neste caso, não é vista de forma completamente negativa. Apesar de o sujeito afirmar o custo financeiro e o caráter de dependência da relação estabelecida entre sua mãe e a "mulher que faz as coisas dela", a afirmação de que o agente terceirizador "não sabe nada", logo vem seguida da observação: "E já viveu quase 80 anos", o que, em nossa compreensão, demonstra a ausência de avaliação negativa da necessidade de terceirização da escrita neste caso específico.

Essas são apenas algumas das situações a nós relatadas como propulsoras da terceirização do ato de escrever. No que diz respeito à leitura, semelhante mecanismo de sobrevivência na sociedade letrada - a terceirização — também é utilizado. 
Vejamos como uma das educandas pesquisadas enfrentou a necessidade de cuidar da manutenção da saúde de seus filhos:

Quando eu tinha que levá-los ao posto, ficava observando as mulheres e perguntava se era lá que estava aplicando as vacinas. Tudo que precisava saber tinha que perguntar. Quando chegava em casa pedia para o meu esposo ler a carteira da vacina e guardava na cabeça o dia que precisava levar de novo. (Informação pessoal)

A idéia de que "tudo que preciso saber tenho que perguntar" esteve constantemente presente nos relatos coletados durante nossa pesquisa com o referido grupo de sujeitos em situação de letramento a-funcional. Em todos os relatos pudemos perceber que a prática da terceirização da escrita nunca foi vivenciada como algo que empodere ou traga bem-estar ao sujeito que nela ocupa o papel de terceirizador. Ao contrário, tal prática tem se configurado como um atalho na contramão da "arte de esquecer como um bem mais importante do que a arte de memorizar", ou seja, a auto-obliteração e a facilidade de "esquecer ao invés de aprender" - características apontadas por Bauman como aspectos importantes da modernidade líquida - não têm favorecido os modos de relação dos sujeitos em letramento a-funcional com o mundo da escrita, sequer sua relação consigo mesmos diante desse mundo.

Prova disso é o reconhecimento da superação da necessidade de terceirização do acesso ao código escrito como algo positivo. Um dos sujeitos revelou-nos:

Depois que eu comecei a estudar e já lia alguma coisinha, um dia, eu fui ao Hospital. Quando eu cheguei no salão que eu entrava sempre, estava fechado, mas estava escrito lá: "nós não estamos mais aqui. Procure o lado esquerdo, número tal." Eu não precisei de ninguém para dizer onde eu tinha que ir. Eu só cheguei lá, quando eu vi a porta fechada e isso escrito, olhei e disse: "Nossa Senhora! Como é bom a pessoa saber ler!” (Informação pessoal)

A sensação de bem-estar decorrente da percepção de que o acesso ao código escrito não depende mais do recurso a uma terceira pessoa, parece ser uma constante nos relatos que avaliam a necessidade desse recurso. Destacamos um trecho que mostra o seu contrário: 
Não é fácil depender dos outros para saber das coisas, tive sorte de nunca ter sido xingada ao pedir uma informação ou uma ajuda para ler e escrever qualquer coisa. Sempre pedi "por favor" e perguntava. Mas, já vi gente levando xingo, vi informando o endereço errado. Nem todo mundo tem a boa vontade para ajudar. (Informação pessoal)

A partir dos excertos acima destacados em cotejamento com a realidade moçambicana, pretendemos tecer algumas considerações sobre esse fenômeno tão antigo e tão moderno: a terceirização da escrita, de modo que possamos estabelecer algumas relações entre os modos de interação de sujeitos em situação de letramento a-funcional com o universo letrado, bem como a respeito dos sentidos e valores atribuídos a tal relação. Para isso, apresentaremos a seguir como o fenômeno da terceirização da escrita tem ocorrido na capital de Moçambique, de modo que possamos traçar alguns paralelos entre duas realidades que, resguardadas suas particularidades, revelam alguns pontos em comum no que diz respeito ao uso terceirizado da escrita em Língua Portuguesa.

\section{Mulheres idosas em Maputo}

De acordo com dados do governo moçambicano (2006), o analfabetismo é preocupante no país, especialmente na zona rural e entre as mulheres. No caso destas, o Ministério da Educação e Cultura estima que, aproximadamente, $70 \%$ não sabem ler e escrever em Língua Portuguesa compondo os dois terços dos 772 milhões de adultos que não dominam a leitura e a escrita no mundo.

Deste contexto, para fins deste artigo, falaremos de mulheres idosas que moram na capital de Moçambique, Maputo, a que oferece melhor qualidade de vida e acesso a bens e serviços do país.

Com relação aos dados gerais da cidade acerca do gênero feminino e da faixa etária desta população, sabemos que, de acordo com os dados preliminares do Censo de 2007, na cidade de Maputo vivem 1.099.102 pessoas; 
destas, 567.308 são mulheres que, de acordo com o World Population Prospects de $1998^{7}$, possuem a seguinte distribuição etária a partir dos $60 \operatorname{anos}^{8}$ :

Tabela 3 - Habitantes do gênero feminino com idade igual ou superior a 60 anos na cidade de Maputo, no final do século XX

\begin{tabular}{|c|c|}
\hline Grupo de idade & Número de habitantes/mulheres \\
\hline $60-64$ & 178 \\
\hline $65-69$ & 134 \\
\hline $70-74$ & 92 \\
\hline $75-79$ & 54 \\
\hline $80+$ & 35 \\
\hline
\end{tabular}

Fonte: World Population Prospects, 1998.

Além desta distribuição etária que localiza os sujeitos com os quais nos deparamos em missão de trabalho em Maputo, faz-se ainda necessário apresentar alguns dados referentes ao universo sócio-econômico no qual estas senhoras idosas estão inseridas. Para tanto, examinemos o excerto da tabela sobre o Índice de Pobreza Humana (IPH), 2000, realizada pelo Instituto Nacional de Estatística de Moçambique:

Tabela 4 - Índice de Pobreza Humana (IPH-1), por Províncias e Moçambique $2000^{9}$

\begin{tabular}{|c|c|c|c|c|c|c|c|}
\hline \multirow{3}{*}{$\begin{array}{l}\text { Região/ } \\
\text { Província }\end{array}$} & \multirow{3}{*}{ IPH } & \multirow{3}{*}{$\begin{array}{l}\text { Privação } \\
\text { de sobre- } \\
\text { vivência }\end{array}$} & \multirow{3}{*}{$\begin{array}{c}\text { Privação } \\
\text { de conhe- } \\
\text { cimento }\end{array}$} & \multirow{3}{*}{$\begin{array}{l}\text { Composto da } \\
\text { privação } \\
\text { dum padrão } \\
\text { de vida ade- } \\
\text { quada }(\%)\end{array}$} & $\begin{array}{r}\text { Privação } \\
\mathrm{a}\end{array}$ & $\begin{array}{l}\text { e condiç } \\
\text { equadas }\end{array}$ & $\begin{array}{l}\text { es de vida } \\
\% \text { ) }\end{array}$ \\
\hline & & & & & \multicolumn{2}{|c|}{ População sem } & \multirow[b]{2}{*}{$\begin{array}{c}\text { Crianças < } \\
5 \text { anos } \\
\text { com peso } \\
\text { deficiente }\end{array}$} \\
\hline & & & & & $\begin{array}{c}\text { Acesso a } \\
\text { Água } \\
\text { potável }\end{array}$ & $\begin{array}{c}\text { Acesso } \\
\text { aos Ser- } \\
\text { viços de } \\
\text { saúde }\end{array}$ & \\
\hline & IPH-1 & $\mathrm{P} 1$ & $\mathrm{P} 2$ & P3 & P3.1 & P3.2 & P3.3 \\
\hline 1 & 2 & 3 & 4 & 5 & 6 & 7 & 8 \\
\hline Nampula & 58.0 & 26.1 & 69.9 & 60.9 & 73.8 & 78.0 & 31.0 \\
\hline
\end{tabular}

${ }^{7}$ Estes dados foram retirados do artigo de Caccia-Bava e Thomaz (2001).

${ }^{8}$ De acordo com a Organização Mundial de Saúde, a partir dos 60 anos, a pessoa é categorizada como "idosa".

${ }^{9}$ Coluna 3: Estimativas para este Relatório com base nas Tabua de Vida do RGPH usando o Modelo Oeste nível 24W.

Coluna 6: Refere-se ao acesso a água canalizada dentro e fora de casa e fontenários.

Coluna 7: Percentagem da população sem serviços / assistência de saúde e saneamento do seguinte tipo: cuidados pré-natais, parto na maternidade ou no centro de saúde; médico; enfermeiro e parteira na aldeia; centro e posto de saúde; latrina e uso de algum método moderno contraceptivo. 


\begin{tabular}{|c|c|c|c|c|c|c|c|}
\hline Centro & 50.6 & 21.6 & 59.0 & 55.7 & 60.3 & 78.8 & 28.1 \\
\hline Zambézia & 63.9 & 28.8 & 74.7 & 70.0 & 82.9 & 93.7 & 33.4 \\
\hline $\begin{array}{l}\text { Maputo } \\
\text { prov. }\end{array}$ & 26.5 & 10.5 & 32.9 & 26.6 & 23.1 & 45.3 & 11.5 \\
\hline $\begin{array}{l}\text { Maputo } \\
\text { cidade }\end{array}$ & 12.2 & 7.5 & 13.0 & 14.1 & 1.4 & 32.6 & 8.2 \\
\hline Moçambique & 48.0 & 20.3 & 56.7 & 52.2 & 58.8 & 71.7 & 26.0 \\
\hline
\end{tabular}

Fonte: INE: IDS, Tabelas de vida, QUIB 2000/01.

Maputo e outros grandes centros urbanos do continente africano são cidades que apresentam os elementos típicos da pós-modernidade e suas facilidades: telefones celulares, aparelhos de fax, computadores com acesso à internet, setor de turismo em desenvolvimento, dentre outras (FASOKUN et alli, 2005). E assim, como demonstraremos abaixo, esta população total de mulheres idosas desta cidade - composta por, aproximadamente, 500 pessoas - pode recorrer, e assim o faz em muitas ocasiões de acordo com os dados coletados, ao processo de terceirização da escrita.

\section{Situações reais de escrita terceirizada}

Em Maputo, entrevistamos 45 pessoas, moradoras da cidade, com idade entre 16 e 50 anos. É importante ressaltar que nenhuma destas pessoas teve a Língua Portuguesa como materna e que a aprenderam, na modalidade escrita, majoritariamente, na instituição escolar. Tais sujeitos, durante nossa missão de trabalho em Maputo no mês de março de 2008, falaram-nos, dentre outros assuntos, sobre suas mães, tias, pessoas conhecidas que, por diferentes motivos, até os dias de hoje, falam poucas palavras em Língua Portuguesa, não dominam a escrita da mesma e, quando sentem necessidade deste instrumento na vida social, costumam pedir para seus filhos e netos que realizem determinadas tarefas para elas próprias.

Tais dados foram coletados na cidade de Maputo em diferentes locais: lojas, bares, supermercados, restaurantes, escolas, bibliotecas, por meio de entrevistas semi-estruturadas. 
Interessante notar que todos os nossos informantes conheciam, e bem, um indivíduo que não domina a Língua Portuguesa, nem falada, nem escrita. Dentre estas pessoas conhecidas, boa parte vivia apenas no ambiente doméstico, dedicando-se ao trabalho tradicionalmente feminino, do lar, utilizando-se de suas línguas maternas e locais para se comunicarem nesta esfera com seus familiares e vizinhos.

Por outro lado, um número menor, não por isso menos significativo para os fins deste artigo, delegava a algum membro da sua família a função de escriba - ou seja, terceirizava a escrita da Língua Portuguesa — da qual falamos no início deste trabalho.

Das entrevistas realizadas com filhos (as), netos (as), sobrinhos (as) das senhoras, sujeitos desta nossa reflexão, vale a pena destacar o que uma de nossas informantes nos disse a respeito de sua mãe:

Eu uso a Língua Portuguesa no meu trabalho e em casa com meus irmãos. Mas quando falo com minha mãe, eu falo em Ronga. Quando minha mãe precisa ler algum documento [em Português], ela pede para mim [sic] fazer esta leitura, já que eu sou a pessoa que mais estudou em casa. Para escrever para alguém, também sou eu que faço isto para minha mãe. Ela diz que não quer saber de aprender esta língua, nem quer ouvir falar em programas de alfabetização. (Informação pessoal)

Também nos chamou a atenção uma das nossas entrevistadas, uma moça de 24 anos, estudante da décima classe, cuja língua materna foi o Ronga e por meio da qual ela se comunica em casa também com sua mãe. Entretanto, neste caso, a irmã mais velha de sua mãe tem sido, ao longo da vida desta família, a escriba e intérprete dos acontecimentos cuja origem é o mundo lusófono, especialmente, aqueles que dizem respeito ao uso de palavras de baixo calão.

No caso de outra das nossas entrevistadas, sendo esta de classe social mais abastada que os demais - uma mulher, com 25 anos, bacharel no curso de turismo - mesmo tendo a língua Changana como materna, aprendeu a falar o Português desde pequena em sua casa, junto da sua mãe. Entretanto, tem sido a escriba de diferentes empregadas domésticas que têm passado 
pela sua casa que, segundo a depoente, não têm condições, nem mesmo muita vontade [sic] de participar das aulas de alfabetização, à exceção de uma delas que depois de um ano matriculada em curso de alfabetização já conseguia escrever algumas palavras.

Em outra direção, temos o depoimento de uma jovem mulher, Bitonga, que aprendeu a Língua Portuguesa em casa, quando pequena, com seu irmão mais velho: Fico emocionada quando me lembro de ter ensinado a minha avó a falar e ler em Português as coisas da nossa escola.

Finalmente, destacamos passagem da entrevista realizada com um dos nossos entrevistados, um homem de 38 anos, com graduação completa, que aprendeu a escrever em Língua Portuguesa na escola com oito anos de idade. Segundo ele, a tia e a mãe, apesar de falarem algumas palavras em Português devido ao contato que têm com seus netos, não sabem ler nem escrever a mesma. Sendo assim, junto a estas suas familiares, falantes de Ronga, faz o papel de escriba e de intermediário entre as gerações mais novas e mais velhas da família. Apesar de sua tia e avó não terem tido interesse, talvez porque ele mesmo supria as necessidades advindas do mundo lusófono, conheceu várias senhoras, em idade avançada, preocupadas em aprender a ler e a escrever em português para gerir seus trabalhos e escrever suas próprias cartas sem recorrer a outros.

\section{Considerações finais}

Terceirização como favor, benevolência ou obrigação. Seja qual for o motivo que a efetive, podemos afirmar que a terceirização da escrita em tempos de modernidade líquida não tem se mostrado como uma vantagem para o agente terceirizador, muito menos vivenciada por ele como uma situação cômoda. Nesse sentido, o estabelecimento da funcionalidade da língua escrita na economia psíquica de cada sujeito pode estar amplamente vinculada com o desejo de superação da necessidade de terceirizar o acesso à cul- 
tura letrada. Em outros termos, asseguramos que o vislumbre de uma nova condição frente às exigências da sociedade grafocêntrica, caracterizada pela independência em situações de acesso ao código escrito, pode ser um importante elemento de definição da funcionalidade da relação entre sujeito-letra e, assim, influenciar positivamente o aprendizado da leitura e da escrita.

Nesse sentido, refletiremos, no âmbito dessas considerações finais, sobre a terceirização da escrita como um dos fenômenos típicos da era atual, designada por Zygmunt Bauman (1999, 2001) como Modernidade Líquida. Consideramos que, ao longo da história do mundo ocidental, muitas outras situações semelhantes já povoaram os registros historiográficos, basta lembrarmos-nos da função dos escribas da antiguidade ao medievo. No entanto, ao nos referirmos à "terceirização da escrita" nos tempos atuais, tratamos de algo bem específico: do modo encontrado, por pessoas em situação de letramento a-funcional, para desempenhar algumas atividades básicas na sociedade grafocêntrica em que vivem, tais como: preencher formulários, assinalar listas de presença em reuniões escolares, assinar recibos, escrever bilhetes e cartas, entre outras ações comuns na vida diária.

Tendo em vista que a cultura letrada tem se constituído como uma marca de inclusão e de exclusão de todos que a ela são sujeitados sem opção de escolha, podemos também refletir sobre os efeitos provocados no sujeito que terceiriza a sua escrita. Trata-se de uma situação cômoda ou algo a ser superado?

De acordo com o exposto, claro está que a terceirização da escrita, especificamente no caso dos sujeitos estudados, tem ocupado um duplo e dicotômico papel: ao mesmo tempo em que favorece a inserção do sujeito na cultura letrada - na medida em que assegura o "cumprimento de tarefas" num contexto social no qual a habilidade de ler e escrever coloca-se, em diversas situações, como algo indispensável —, ela também confere a este mesmo sujeito uma desconfortável posição de dependência oriunda justamente de sua tentativa de inserção, via um terceiro sujeito, no universo 
letrado. Essa dependência tem operado, sobretudo no caso brasileiro em que a necessidade de interação com o universo letrado parece ser mais constante, como um dos componentes de dilapidação da auto-estima dos indivíduos que se vêem a mercê da boa-vontade alheia, cada vez mais rara nessa era marcada pelo desengajamento mútuo, pela evitação e pela procrastinação.

Lançados, muitas vezes, em situações humilhantes para conseguir cumprir tarefas que exigem domínio da escrita, os sujeitos em situação de letramento a-funcional que recorrem à terceirização da escrita, diferentemente dos patrões que terceirizam algumas atividades de suas empresas, estão muito longe de gozar de uma situação vantajosa para consecução de seus fins.

Enquanto nas empresas o modelo terceirizante é nitidamente prejudicial ao trabalhador, por ter sido criado com o intuito de reduzir salários e enfraquecer os sindicatos (OLIVEIRA, 2008), no cotidiano dos sujeitos estudados esse modelo fragiliza aquele que faz o "papel do patrão", ou seja, numa analogia de hierarquia de vantagens e poderes na terceirização da escrita há uma espécie de inversão de valores em relação à terceirização tradicional: quando se trata de terceirizar a escrita, quem a determina ocupa um lugar social inferior em relação ao daquele que obedece ao seu comando. Em outras palavras, há uma perversa inversão de papéis na qual o comando é acatado mais pela inspiração de piedade ou bondade que por uma autoridade que o sustente ou legitime, ao passo que a disponibilidade para o papel de sujeito terceirizado é impulsionada pela comiseração viável desde que não atrapalhe outras demandas do próprio sujeito.

Face ao exposto, compreendemos que, apesar de algumas mulheres idosas africanas não demonstrarem grande interesse em aprender a ler e a escrever em Língua Portuguesa - movidas por razões culturais que fogem dos limites deste artigo —, a terceirização da escrita é uma estratégia de inserção no universo letrado que urge ser substituída por outras formas de interação, pautadas na autonomia do sujeito que, por ora, tem ocupado o 
papel de agente terceirizador. O caminho apontado mais freqüentemente, pelos próprios sujeitos investigados, para essa substituição, consiste no aprendizado da língua escrita, não só no que diz respeito à técnica de codificação e decodificação, mas também no domínio da interpretação dos diversos tipos de produção escrita e, conseqüentemente, variadas formas de produção da mesma.

Muito além de uma constatação aparentemente óbvia, a defesa do domínio da língua escrita tem sido apontada como forma de superação da terceirização dos usos da escrita justamente num momento histórico em que os habitantes das grandes cidades têm demonstrado preferência em terceirizar muitas outras funções da vida cotidiana: para que ir ao banco, se posso contratar um motoboy? Para que levar os filhos à escola, se posso colocá-lo numa perua escolar? Para que preparar o almoço de domingo, se posso solicitá-lo pelo telefone? Para que preencher a "papelada lá do sítio", se posso pagar para alguém fazer isto por mim?

Sabemos que, por razões de ordem econômica, algumas dessas situações estão fora da realidade dos sujeitos até então mencionados. No entanto, são exemplos corriqueiros de maneiras como temos nos relacionado com um mundo que exige de nós, vertiginosamente, agilidade e bons resultados: no trabalho, nos estudos, nos relacionamentos interpessoais; enfim, em todas as esferas do existir humano.

Render-se à lógica dos tempos atuais ou empreender estratégias de resistência e sobrevivência no mundo letrado? Este é o grande desafio colocado diante dos sujeitos em situação de letramento a-funcional na era da modernidade líquida. Cabe a nós, educadores e pesquisadores no campo da alfabetização e do letramento, compreendermos as tensões inerentes aos modos de estar no mundo desses sujeitos e refletir sobre as possibilidades de superação e enfrentamento das questões que mais mobilizam os indivíduos que habitam nosso campo de ação. Um bom início de caminho seria compreender a aprendizagem da leitura e da escrita como algo muito maior que 
uma simples transmissão de conhecimento sobre uma técnica de codificação-decodificação culturalmente valorizada. Para estar a serviço da efetiva superação da necessidade de terceirização da escrita, o ensino não pode perder de vista os desejos que os aprendentes têm em relação ao seu aprendizado. Precisamos ouvir plenamente apelos do tipo: "o dia mais feliz da minha vida será quando eu não depender mais de ninguém para preencher essa porcaria dessa ficha do hospital!”

Só quando apelos desse tipo forem realmente ouvidos, acolhidos e utilizados, pelos alfabetizadores, como marco referencial para a construção de saberes sobre a escrita, a necessidade de sua terceirização estará efetivamente com seus dias contados. Podemos também reiterar estas considerações finais à luz de um dos contos mais emocionantes da literatura moçambicana, O Sonho de Alima, de Lília Momplé.

Tal conto fala sobre a vida de Alima, uma mulher que, desde o momento de nascer, sabia o que queria. Cresceu em uma família pobre, cujos pais não dominavam a Língua Portuguesa e, assim como a sociedade em que viviam, não valorizavam a educação escolar feminina. A personagem principal, ao ver seus irmãos estudando, nutriu em si o sonho de ler e escrever em Língua Portuguesa.

Teve esta oportunidade, diferentemente das outras moças da região, apenas depois de se casar, ainda que com todos os obstáculos colocados pelo seu marido. Ela se casou com um ourives negro aos dezoito anos. Quando manifestou a ele sua vontade de estudar, este foi contra, exigindo que ela escolhesse entre ele e os estudos. Alima escolheu estudar e voltou para a casa da família, que a rejeitou, assim como a maioria da comunidade.

Começou a estudar e, a pedido do marido que aceitou deixá-la estudar, retomou o casamento. Após a interrupção dos estudos pela guerra, com mais dois anos concluiu o curso de alfabetização que tinha sido o seu grande sonho e, finalmente, aprendeu a ler e a escrever, abandonando a possibilidade de se servir da terceirização da escrita. 
De acordo com os dados coletados em Maputo, muitas das mulheres idosas que ainda se encontram na dependência de um agente terceirizado para cumprir tarefas do mundo letrado não demonstram o mesmo "sonho de Alima”. Uma análise da resistência para se alfabetizar em Língua Portuguesa, língua oficial e não-materna em dissonância com a realidade brasileira, demandaria uma nova reflexão e um novo artigo. Por ora, ressaltamos apenas a necessidade de muitos outros estudos sobre a terceirização da escrita empreendida pelos usuários da Língua Portuguesa no Brasil, especialmente no que diz respeito às relações estabelecidas entre os sujeitos e a língua herdada pelos colonizadores. Aspectos culturais não podem ser negligenciados na tentativa de elucidação do objeto de estudo proposto e, por isso, reforçamos a importância da efetiva implementação da Lei 11.645/08:

Tal proposta pretende integrar a elaboração de um corpus prático-teórico com a finalidade de compor parâmetros curriculares de abordagem étnico-raciais, favorecendo a adequação desta temática na educação básica, uma vez que se pretende constituir como subsídio para a Lei $11.645 / 08$, que estabelece como obrigatório o estudo da História e Cultura AfroBrasileira e Africana, e também Indígena, em salas de aula. Tal legislação, como sabemos, vem exigindo modalidades de atualização continuada para educadores, tanto para repertório informativo específico como para formação de excelência na matéria (SILVA; BERCHIOR, 2008).

Nesse sentido, pretendemos fazer deste artigo um passo inicial no caminho da construção de um corpus teórico sobre a terceirização da escrita como estratégia de inserção no mundo lusófono letrado no contexto da modernidade líquida e esperamos, assim, contribuir para a ampliação do conhecimento sobre a cultura africana nesse início de século XXI. 


\section{Referências bibliográficas}

BAUMAN, Zygmunt (1999). Modernidade e ambivalência. Rio de Janeiro: Jorge Zahar Editor.

(2000). Em busca da política. Rio de Janeiro: Jorge Zahar Editor.

(2001). Modernidade líquida. Rio de Janeiro: Jorge Zahar Editor.

(2003). Comunidade. Rio de Janeiro: Jorge Zahar Editor.

BRASIL. Lei 11.645/08. Altera a Lei 9.394, de 20 de dezembro de 1996, Modificada pela Lei 10.639, de 9 de janeiro de 2003, que estabelece as Diretrizes e Bases da Educação Nacional, para incluir no currículo oficial da rede de ensino a obrigatoriedade da temática história e cultura afro-brasileira e indígena.

CACCIA-BAVA, Emiliano de Castro e; THOMAZ, Omar Ribeiro (2001). Moçambique em movimento: dados quantitativos. In: FRY, Peter (Org.). Moçambique: ensaios. Rio de Janeiro: Editora da UFRJ, p. 21 a 60.

COSTA, Patrícia C. Sem medo de ser falante: as conquistas da oralidade por educandas idosas no Mova-Guarulhos. 2008. 197 f. Dissertação (Mestrado) - Faculdade de Educação, Universidade de São Paulo, São Paulo, 2008 .

FASOKUN, Thomas et alli. 2005. The psychology of adult learning in Africa: African perspectives on adult learning. Unesco: Institute for Education.

INSTITUTO BRASILEIRO DE GEOGRAFIA E ESTATÍSTICA. Brasil já tem mais de 180 milhões de habitantes. Disponível em: <http://www.ibge. gov.br>. Acesso em: 31 ago. 2004.

Produto Interno Bruto dos Municípios. Disponível em: <http://ww w.ibge.gov.br>. Acesso em: 27 nov. 2007.

MANACORDA, Mario A. (2004). História da Educação: da antiguidade aos nossos dias. 11. ed. São Paulo: Cortez.

MOMPLÉ, Lília. O sonho de Alima. In: Os olhos da cobra verde. Maputo: Associação dos Autores Moçambicanos, s.d. 
OLIVEIRA, Murilo C. S. Pós-fordismo e reflexos nos contratos de trabalho. Disponível em: <http://ojs.c3sl.ufpr.br/ojs2/index.php/direito/article/vi ew File/7038/5014>. Acesso em: 7 maio 2008.

SEBRAE. O que é terceirização? Disponível em: <http://www.sebraesp. com.br/principal/abrindo\%20seu\%20neg\%C3\%B3cio/produtos\%20sebrae/a rtigos/lista deartigos/terceirizacao.aspx>. Acesso em: 1 maio 2008.

SILVA, Nilce da. Falar, ler, escrever: um estudo sobre o processo de formação de adultos lusófonos em situação de pouca escolarização. 2001, 222 f. Tese (Doutorado em Educação) - Faculdade de Educação, Universidade de São Paulo, São Paulo, 2001.

(2003). Exclusão social: espaço de criação como alternativa educacional. São Paulo: Ieditora.

; BERCHIOR Aparecida do Carmo Frigeri (2008). Fragmentos da memória: cultura e língua portuguesa em Maputo, homenagem aos irmãos moçambicanos. Revista Acoalfaplp: acolhendo a alfabetização nos países de língua portuguesa, São Paulo, ano 3, n. 5, 2008. Disponível em: <http://www.acoalfaplp.net/>. Publicado em: setembro 2008.

; CASCAPERA, Claudia. Espaço de criação segundo Biarnès. Jornal da USP. Ano XVIII, n. 662, de 13 a 19 de outubro de 2003. Disponível em: <http://www.usp.br/jorusp/arquivo/2003/jusp662/pag02.htm>. Acesso em: 8 jul. 2005.

\section{AUTORAS}

\section{Nilce da SILVA}

Filiação institucional: FEUSP

E-mail: nilce@usp.br

\section{Patrícia Claudia da COSTA}

Filiação institucional: Secretaria Municipal de Educação de Guarulhos E-mail: guaruspeleo@yahoo.com.br 


\section{Como citar este artigo:}

SILVA, Nilce da e COSTA, Patrícia Claudia da. O aprendizado da língua portuguesa em tempos de modernidade líquida: algumas considerações sobre a aprendizagem da leitura e da escrita de pessoas idosas no Brasil e em Moçambique. Revista ACOALFAplp: Acolhendo a Alfabetização nos Países de Língua portuguesa, São Paulo, ano 3, n. 5, 2008. Disponível em: <http://www.acoalfaplp.net>. Publicado em: setembro 2008. 